\title{
Salt intrusion in multi-channel estuaries: a case study in the Mekong Delta, Vietnam
}

\author{
A. D. Nguyen ${ }^{1,2}$ and H. H. G. Savenije ${ }^{1,2}$ \\ ${ }^{1}$ Department of Management and Institutions, UNESCO-IHE Institute for Water Education, 7 Westvest, P.O. Box 3015, 2601 \\ DA Delft, The Netherlands \\ ${ }^{2}$ Water Resources Section, Faculty of Civil Engineering and Applied Geosciences, Delft University of Technology, Stevinweg \\ 1, P.O. Box 5048, 2600 GA Delft, The Netherlands
}

Received: 6 December 2005 - Published in Hydrol. Earth Syst. Sci. Discuss.: 13 April 2006

Revised: 10 October 2006 - Accepted: 10 October 2006 - Published: 16 October 2006

\begin{abstract}
There is a well-tested theory for the computation of salt intrusion in alluvial estuaries that is fully analytical and predictive. The theory uses analytical equations to predict the mixing behaviour of the estuary based on measurable quantities, such as channel topography, river discharge and tidal characteristics. It applies to single-channel topographies and estuaries that demonstrate moderate tidal damping. The Mekong delta is a multi-channel estuary where the tide is damped due to a relatively strong river discharge (in the order of $2000 \mathrm{~m}^{3} / \mathrm{s}$ ), even during the dry season. As a result the Mekong is a strongly riverine estuary. This paper aims to test if the theory can be applied to such a riverine multichannel estuary, and to see if possible adjustments or generalisations need to be made. The paper presents salt intrusion measurements that were done by moving boat in 2005, to which the salt intrusion model was calibrated. The theory has been expanded to cater for tidal damping. Subsequently the model has been validated with observations made at fixed locations over the years 1998 and 1999. Finally it has been tested whether the Mekong calibration fits the overall predictive equations derived in other estuaries. The test has been successful and led to a slight adjustment of the predictive equation to cater for estuaries that experience a sloping bottom.
\end{abstract}

\section{Introduction}

The recent book on Salt Intrusion and Tides in Alluvial Estuaries (Savenije, 2005) presents a comprehensive theory for the modelling of steady state and unsteady state salt intrusion in alluvial estuaries. It is based on the analysis of some 17 estuaries world-wide on the basis of which a general predictive theory has been developed that is claimed to be predictive,

Correspondence to: A. D. Nguyen

(d.nguyen@unesco-ihe.org) meaning that it can be applied to predict the salinity distribution in any alluvial estuary provided some basic information on topography, tide and river discharge is known (Savenije, 1986, 1989, 1993). Limitations of the theory are that it has been derived for single channel estuaries and for estuaries where the tide experiences only modest damping or amplification. The Mekong Delta is an alluvial estuary that consists of many branches and that transports a large amount of fresh water to the sea, even during the dry season (in the order of $2000 \mathrm{~m}^{3} / \mathrm{s}$ ). As a result, the tide is strongly damped and the branches of the delta are rather prolonged. This gives the Mekong estuary a clearly riverine character, putting it at the fringe of applicability of this theory.

Looking at other branched alluvial estuaries in the world, it appears that they have similar characteristics: (i) If an estuary is divided into two branches by an island, the branches are of almost equal length. (ii) There are no large differences between the branches in area, width and depth. Examples of branched estuaries are the Loire estuary in France, the Tanintharyi estuary in Myanmar, the Hau and CoChien branches of the Mekong Delta in Vietnam, the Dhamra estuary in India and the Yangtze river estuary in China (see Fig. 1)

The question now is: does the method of Savenije (2005) also apply to these estuaries, or is there a need to extend the theory so that it can be applied to branched estuaries as well. In this paper, we shall demonstrate that the method is indeed applicable to branched estuaries but that a certain procedure needs to be followed. We also present some refinements to the method for estuaries that experience strong tidal damping or that have a prominent bottom slope.

\section{Summary of the method}

Savenije (2005, p. 144) demonstrated that the steady state salt balance equations for High Water Slack (HWS), Low Water

Published by Copernicus GmbH on behalf of the European Geosciences Union. 

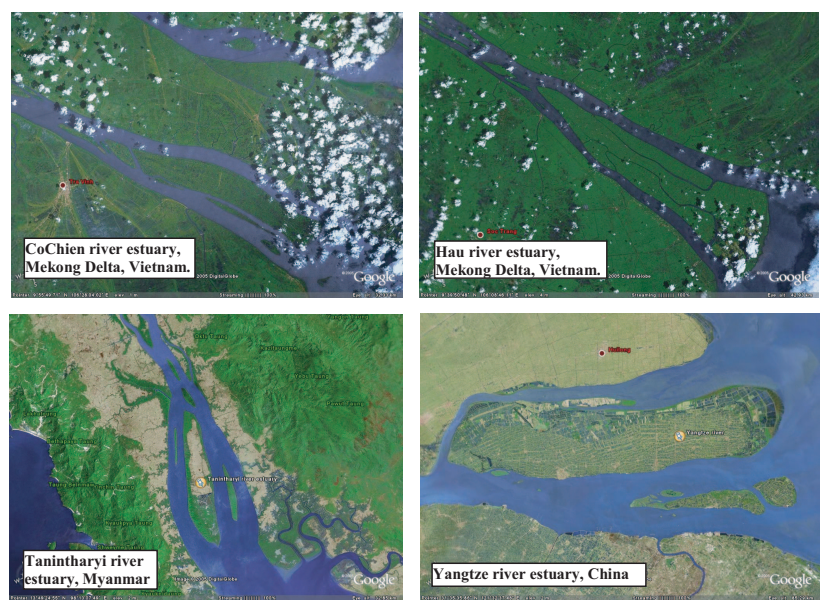

Fig. 1. Some examples of branched estuaries (source: Google Earth).

Slack (LWS) and Tidal Average (TA) situation can be written as:

$S_{i}-S_{f}=c_{i} \frac{d S_{i}}{d x}$

Where $i=1,2,3$ indicating the three different states: HWS, LWS and TA. $S_{i}$ is the steady state salinity, $S_{f}$ is the fresh water salinity. The coefficient $c_{i}$ is an x-dependent coefficient defined by:

$c_{i}=\frac{A}{Q_{f}} D_{i}$

Where $D_{i}\left(\mathrm{~L}^{2} \mathrm{~T}^{-1}\right)$ is the dispersion coefficient for each state $i, Q_{f}\left(\mathrm{~L}^{3} \mathrm{~T}^{-1}\right)$ is the river discharge, which is negative since the positive $\mathrm{x}$-axis points upstream, and $A\left(\mathrm{~L}^{2}\right)$ is the tidal averaged cross-sectional area. The relationship between the salinity and the dispersion coefficient, based on previous work by Van der Burgh (1972) is defined by:

$\frac{d D_{i}}{d x}=K \frac{Q_{f}}{A}$

Where $K(-)$ is the Van der Burgh's coefficient, which has a value between 0 and 1 . This equation can be integrated for an estuary with an exponentially varying cross-section (see Eq. 10) to yield the expression for the dispersion along the estuary:

$$
\frac{D_{i}}{D_{0 i}}=1-\beta_{i}\left(\exp \left(\frac{x}{a}\right)-1\right)
$$

With: $\beta_{i}=-\frac{K a Q_{f}}{D_{0 i} A_{0}}=\frac{K a}{\alpha_{0 i} A_{0}}$ and $\alpha_{0 i}=-\frac{D_{0 i}}{Q_{f}}$

where $D_{0 i}\left(\mathrm{LT}^{-2}\right)$ is the boundary condition at the river mouth $(x=0)$ for HWS, LWS or TA conditions, $A_{0}\left(\mathrm{~L}^{2}\right)$ is the tidal average cross-sectional area at the estuary mouth and $a$ (L) is the convergence length of the cross-sectional area (see Eq. 10). $\alpha_{0 i}\left(\mathrm{~L}^{-1}\right)$ is the mixing coefficient at the estuary mouth. The values of $K$ and $\alpha_{0 i}$ can be obtained through calibration against measured longitudinal salinity distributions at HWS or LWS.

The longitudinal variation of the salinity can be computed through combination of Eqs. (1), (2) and (3):

$$
\frac{S_{i}-S_{f}}{S_{0 i}-S_{f}}=\left(\frac{D_{i}}{D_{0 i}}\right)^{\frac{1}{K}}
$$

where $S_{0 i}\left(\mathrm{ML}^{-3}\right)$ is the boundary salinity at the estuary mouth (for HWS, LWS and TA conditions) and $S_{f}$ is the upstream boundary salinity of the river water. The salt intrusion curve derived for the TA situation, which represents the TA longitudinal variation of the salinity, can be used for LWS and HWS as well, by shifting the curve upstream or downstream over half the tidal excursion $E$.

The salt intrusion length $L_{i}$ can be obtained by substitution of $S_{i}=S_{f}$ in Eqs. (4) and (5), yielding:

$L_{i}=a \ln \left(\frac{1}{\beta_{i}}+1\right)$

Where $L_{i}(\mathrm{~L})$ is the salt intrusion length at HWS, LWS or TA.

Because the method has been applied in 17 different estuaries all over the world, particularly for the HWS situations, it was possible to derive two predictive equations for $\mathrm{K}$ and $D_{0}^{\mathrm{HWS}}$ (Savenije, 1993). These relations were generalised and improved by Savenije (2005, p. 166-169) into:

$D_{0}^{\mathrm{HWS}}=1400 \frac{\bar{h}}{a} \sqrt{N_{R}}(v E)$

and

$$
\begin{aligned}
K= & 0.2 \times 10^{-3}\left(\frac{E}{H}\right)^{0.65}\left(\frac{E}{C^{2}}\right)^{0.39} \\
& (1-\delta b)^{-2.0}\left(\frac{b}{a}\right)^{0.58}\left(\frac{E a}{A_{0}}\right)^{0.14}
\end{aligned}
$$

Where $A_{0}\left(\mathrm{~L}^{2}\right)$ is the cross-sectional area at the estuary mouth, $b(\mathrm{~L})$ is the width convergence length; $C\left(\mathrm{~L}^{0.5} / \mathrm{T}\right)$ is the coefficient of Chezy, $\delta\left(\mathrm{L}^{-1}\right)$ is the damping rate of tidal range; $E(\mathrm{~L})$ is the tidal excursion, which is the distance that a water particle travels between LWS and HWS, obtained from the observed salinity distributions; $v\left(\mathrm{LT}^{-1}\right)$ is the tidal velocity amplitude; $H(\mathrm{~L})$ is the tidal range, $\bar{h}(\mathrm{~L})$ is the constant tidal average depth along the estuary, $N_{R}(-)$ is the Estuarine Richardson number given by: $N_{R}=\frac{\Delta \rho}{\rho} \frac{g h Q_{f} T}{A_{0} E v^{2}}$, and $T(\mathrm{~T})$ is the tidal period. In ideal estuaries, the tidal range, the tidal velocity amplitude, the tidal excursion and the depth are constant along the estuary, while the convergent lengths of the width and the cross-sectional area are equal: $b=a$. In estuaries where there is a certain degree of damping or amplification, the ratio of $H / E$ is still constant, but values of $E$ and $v$ vary along the estuary. Finally if $a \neq b$ there is a bottom slope and the depth is not constant. In the Mekong estuary 
Table 1. Estuarine characteristics of 4 branches in the Mekong Delta.

\begin{tabular}{ccccccccc}
\hline River & Estuary & $\begin{array}{c}A_{0} \\
\left(\mathrm{~m}^{2}\right)\end{array}$ & $\begin{array}{c}B_{0} \\
(\mathrm{~m})\end{array}$ & $\begin{array}{c}\bar{h} \\
(\mathrm{~m})\end{array}$ & $\begin{array}{c}H_{0} \\
(\mathrm{~m})\end{array}$ & $\begin{array}{c}a \\
(\mathrm{~km})(\mathrm{km})\end{array}$ & $\begin{array}{c}b \\
(\mathrm{~km})\end{array}$ \\
\hline \multirow{3}{*}{ Hau river } & Dinh An branch & 18400 & 3400 & 7.1 & 2.8 & 100 & 35 & 55 \\
& Tran De branch & 8200 & 1500 & 5.4 & 2.9 & $\infty$ & $\infty$ & $\infty$ \\
& Combined Hau estuary & 26500 & 4900 & 7.5 & 2.85 & 105 & 51 & 100 \\
& & & & & & & & \\
& & 11100 & 1600 & 6.0 & 2.1 & 75 & 75 & $\infty$ \\
Co Chien river & Co Chien branch & 13200 & 2500 & 5.3 & 2.1 & 32 & 31 & $\infty$ \\
& Cung Hau branch & 24300 & 4100 & 6.2 & 2.1 & 65 & 56 & 400 \\
\hline
\end{tabular}

Note: The values for the width, depth and cross-sectional area were measured at Mean Sea Level (MSL).

$H_{0}$ is the tidal range at the mouth.

branches these latter situations apply, and subsequently special procedures need to be developed.

The assumption made in Eq. (1) to arrive at the steady state equation for conservation of mass, requires that in the estuary an equilibrium condition is reached between, on the one hand, advective salt transport through the downstream flushing of salt by the fresh water discharge, and on the other hand, the full range of mixing processes. To investigate how quickly an estuary system adjusts to a new situation, Savenije (2005, p. 152) proposed an expression derived for the system response time as a function of the steady state salinity distribution. If the time required for the system to adjust is not too long in relation to the variation of the boundary conditions, then a steady state model may be used. The expression reads:

$T_{S} \approx-\frac{1}{Q_{f} S(L / 2)} \int_{L / 2}^{L} A S d x$

Where: $T_{S}(\mathrm{~T})$ is the system response time, which represents the time required for the system to adjust itself from one steady state to another. $S(-), L(\mathrm{~L})$ and $A\left(\mathrm{~L}^{2}\right)$ are the salinity, salinity intrusion length and cross-sectional area for the tidal average situation, respectively.

\section{The Mekong Delta in Vietnam}

\subsection{Overview}

The Mekong river when it enters Vietnam splits into two branches, the Bassac (known as Hau river in Vietnam) and the Mekong (known as Tien river in Vietnam). The two branches form the Mekong delta. The Hau river is the first branch of the Mekong. When the Hau approaches the sea, it splits into two branches: Tran De and Dinh An. The Tien river is the second branch of the Mekong river system. At Vinh Long, the Tien separates into two river branches: Co Chien and My Tho. At a distance of $30 \mathrm{~km}$ from the South

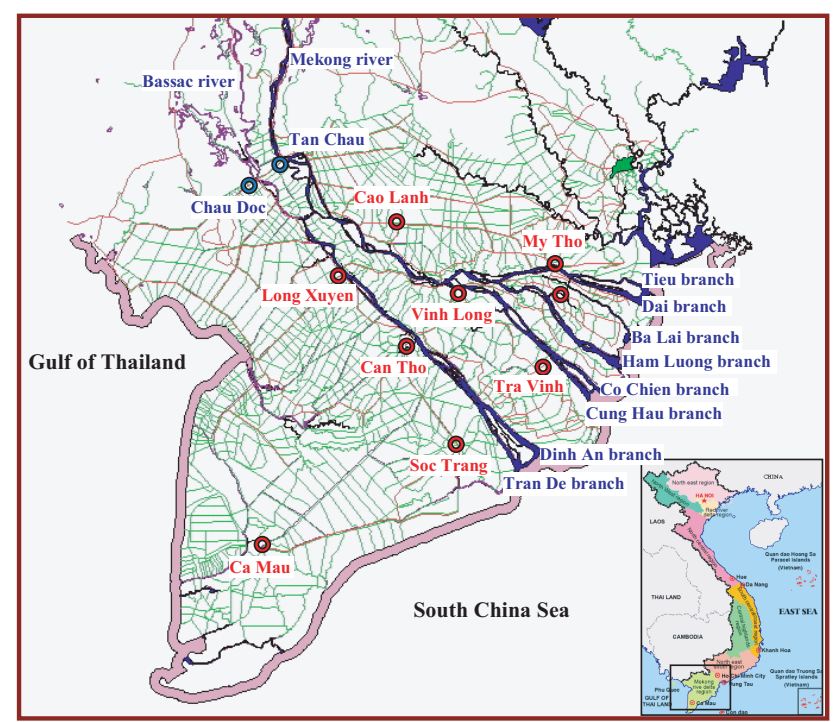

Fig. 2. The Mekong Delta.

China Sea, the Co Chien River again splits into two estuary branches, Co Chien and Cung Hau (see Fig. 2). Although there are more estuary branches: Tieu, Dai, Ba Lai and Ham Luong, this paper concentrates on these four estuary branches: Tran De, Dinh An, Cung Hau and Co Chien.

Tides in the South China Sea have a mixed diurnal and semi-diurnal character. The amplitude can be up to $3 \mathrm{~m}$. There are generally two troughs and two peaks during a day, but their relative height varies over a fortnight. When the first trough decreases from day to day, the other trough increases, and vice versa (See Fig. 3).

As a typical delta, the Mekong delta is affected by both river floods and tide. In the past (before 1980), every year during the dry season, agricultural areas in the Mekong delta were affected by salinity, amounting to 1.7-2.1 million ha out of 3.5 million ha. In the 1980's and 1990's, a number of salinity control projects were implemented, leading to 
Table 2. River discharge and tidal range data in the Mekong estuaries.

\begin{tabular}{cccc}
\hline Estuary name & Date & $\begin{array}{c}\text { River discharge } \\
\left(\mathrm{m}^{3} / \mathrm{s}\right)\end{array}$ & $\begin{array}{c}\text { Tidal range } \\
(\mathrm{m})\end{array}$ \\
\hline \multirow{3}{*}{$\mathrm{Hau}$} & 8 April 2005 & 1064 & 2.89 \\
& 9 April 2005 & 1038 & 2.90 \\
& 21 May 2005 & 930 & 2.62 \\
& 22 May 2005 & 975 & 2.75 \\
\multirow{3}{*}{ Co Chien - Cung Hau } & 21 April 2005 & 680 & 2.07 \\
& 22 April 2005 & 655 & 2.14 \\
\hline
\end{tabular}

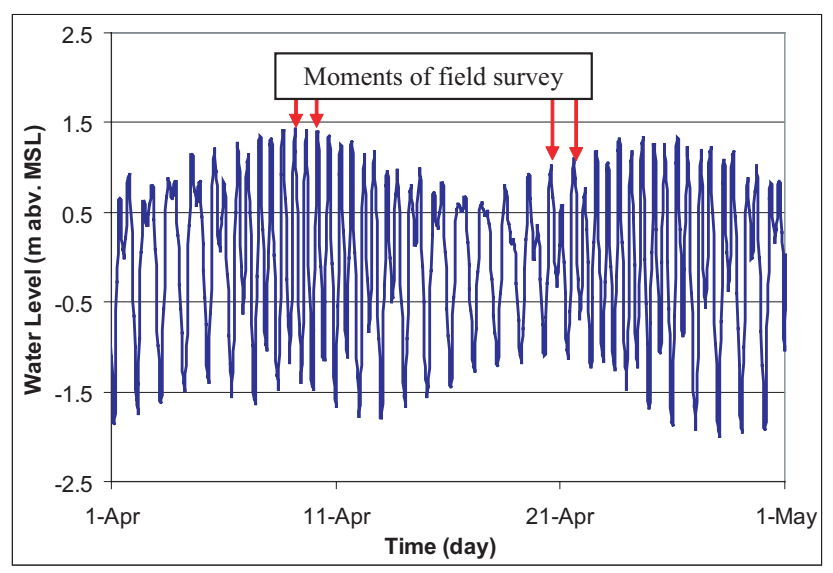

Fig. 3. Water level at the My Thanh station located near the mouth of the Tran De estuary branch (Period from 1 April 2005 to 1 May 2005).

closure dams and sluice gates in the navigation canals connecting the branches of the delta. Nowadays, salinity affects only 0.8 million ha every year. However, the fresh water intakes along the estuary branches are usually affected by high salinity (Nguyen and Nguyen, 1999). Every year, these intakes have to be closed for considerable periods of time (varying from several weeks to one or two months) to prevent salt intrusion.

\subsection{The shape of the Mekong Delta estuaries}

The Dinh An, Tran De, Co Chien and Cung Hau are four branches of a branched estuary system. We shall investigate if it is possible to combine paired branches into a single branch, which would not only simplify the computation, but could also enhance the overall performance of the salt intrusion model. Moreover since we expect that the estuary system functions as an entity, it could very well be that combining paired branches into a single branch is more in agreement with the physical laws that guide the formation of ebb and flood channels than a separate treatment.
The estuary shape of the Tran De - Dinh An and the Co Chien - Cung Hau can be described by the exponential functions:

$A=A_{0} \exp \left(-\frac{x}{a}\right)$

$B=B_{0} \exp \left(-\frac{x}{b}\right)$

and

$h=h_{0} \exp \left(-\frac{x}{d}\right)$

Where $A\left(\mathrm{~L}^{2}\right), B(\mathrm{~L})$ and $h(\mathrm{~L})$ are the cross-section area, width and depth at the location $x(\mathrm{~km})$ from the mouth, respectively. $A_{0}\left(\mathrm{~L}^{2}\right), B_{0}(\mathrm{~L})$ and $h_{0}(\mathrm{~L})$ are the area, width and at the mouth. Finally, $a(\mathrm{~L}), b(\mathrm{~L})$ and $d(\mathrm{~L})$ are the area, width and depth convergence length, respectively. It follows that $d=a b /(b-a)$. The cross-section area and width are obtained from observations, defined at the tidal averaged water level (this level is close to mean sea level). The convergence length, which is the length scale of the exponential function, is obtained by calibration of Eqs. (10), (11) and (12) against measured data. It can be seen very clearly in Fig. 4, Fig. 5 and Table 1 that the paired branches indeed behave as a single estuary with a regular topography according to Eqs. (10-12).

\section{Data sets of the Mekong Delta estuaries}

Salinity data of the Mekong Delta used in this paper consist of two sets: (i) The first set is from field measurements carried out by the authors during the dry season of 2005 and (ii) the second set is from data of a network of fixed stations along the estuaries.

The authors carried out field measurements on the Hau river in the dry season of 2005 , using the "moving boat" method described by Savenije $(1989,1992)$. The method applied to the Mekong Delta estuaries can be summarized as follows: To obtain the salt intrusion curve at HWS or LWS one has to travel at the same speed as the tidal wave. Before the start of the measurement one identifies clearly recognizable points along the estuary at about $3 \mathrm{~km}$ interval (inlets, 

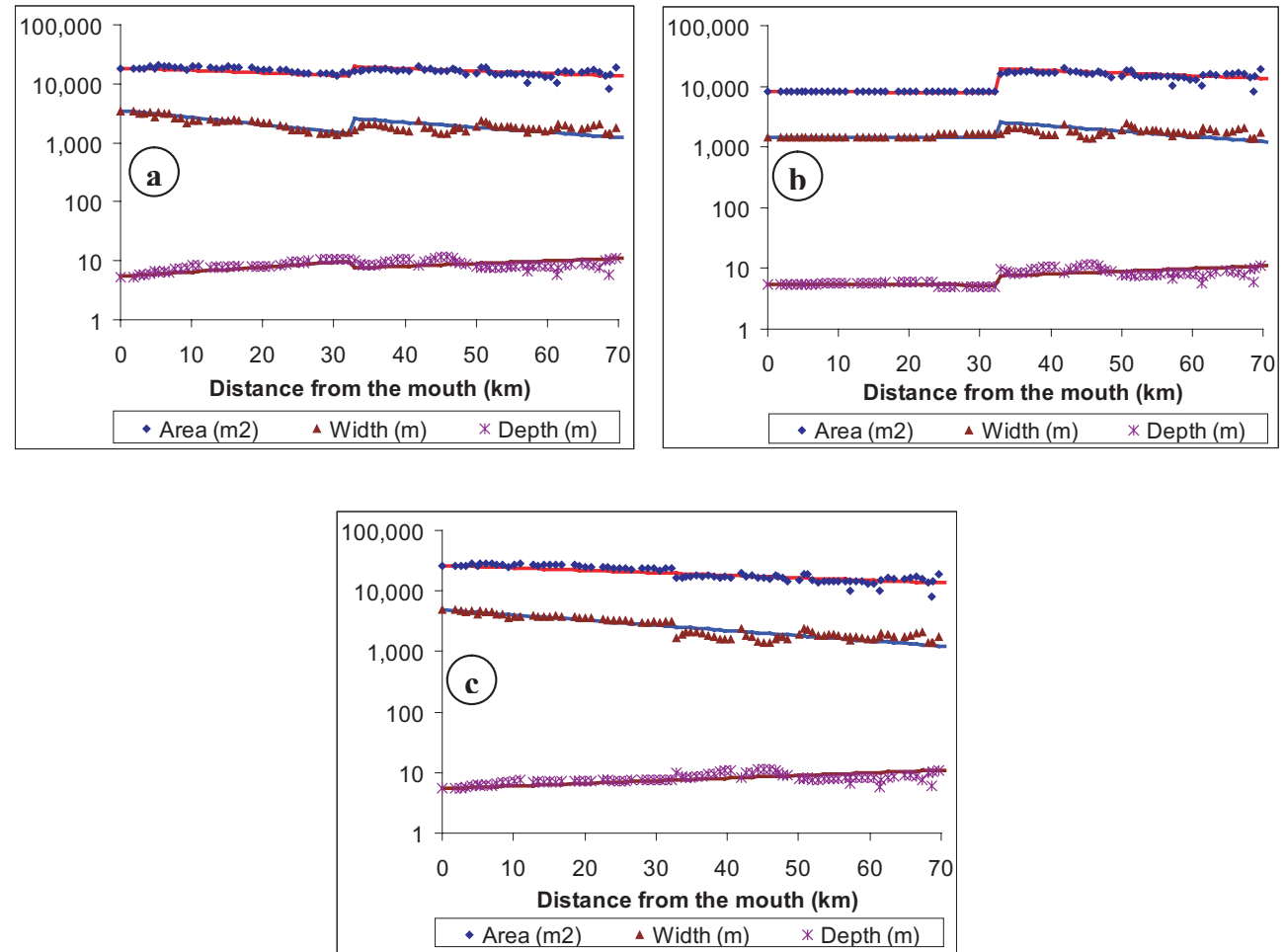

Fig. 4. Shape of the individual branches (a) Tran De and (b) Dinh An. (c) Shape of the Hau (combination of Tran De and Dinh An) estuary, showing cross-sectional area $\left(\mathrm{m}^{2}\right)$ (diamonds), width $(\mathrm{m})$ (triangles) and depth $(\mathrm{m})$ (crosses).
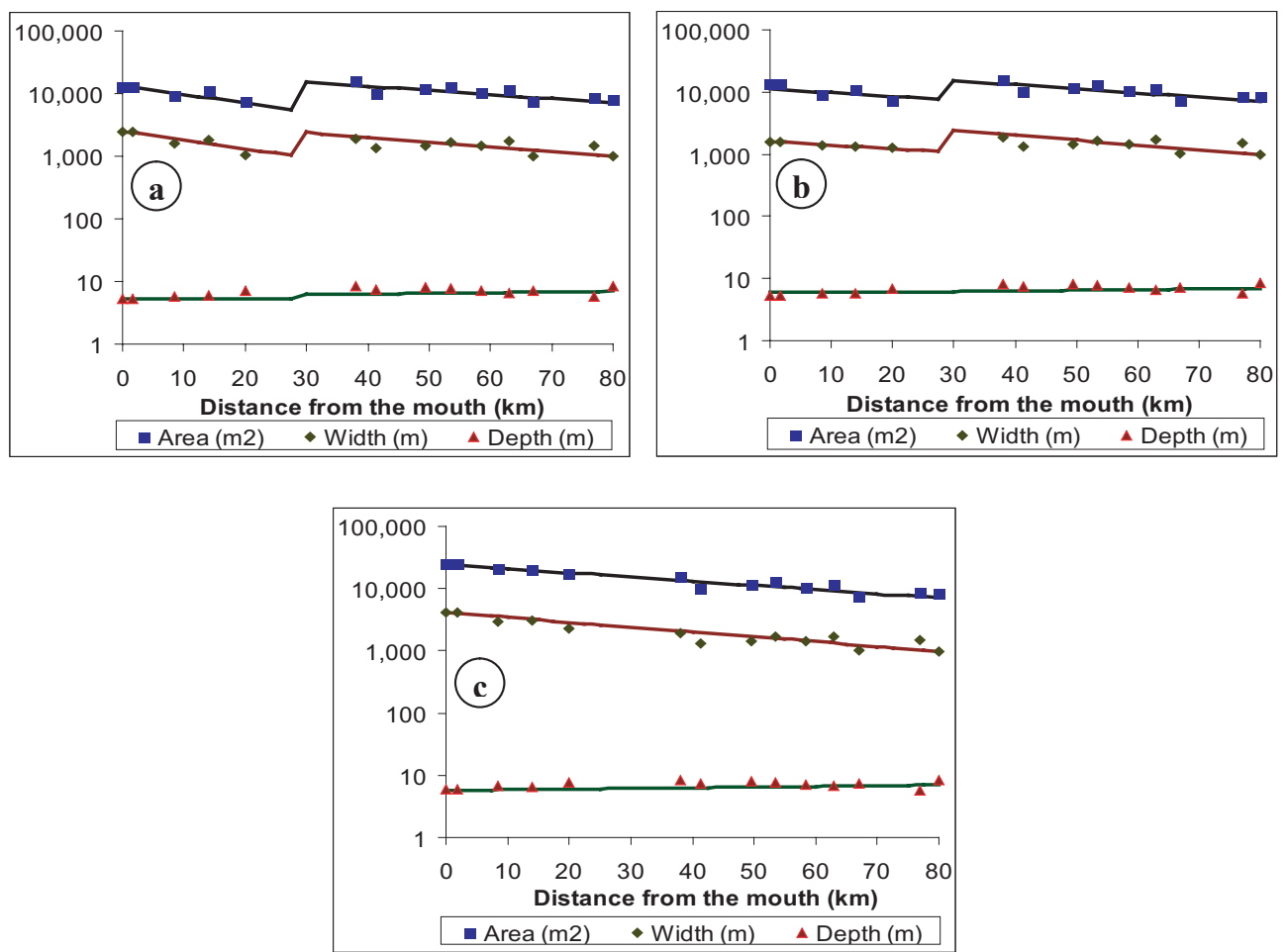

Fig. 5. Shape of the individual branches: (a) Cung Hau and (b) Co Chien. (c) Shape of the Co Chien - Cung Hau (combination of Co Chien and Cung Hau) estuary, showing cross-sectional area $\left(\mathrm{m}^{2}\right)$ (diamonds), width $(\mathrm{m})$ (triangles) and depth (m) (crosses). 

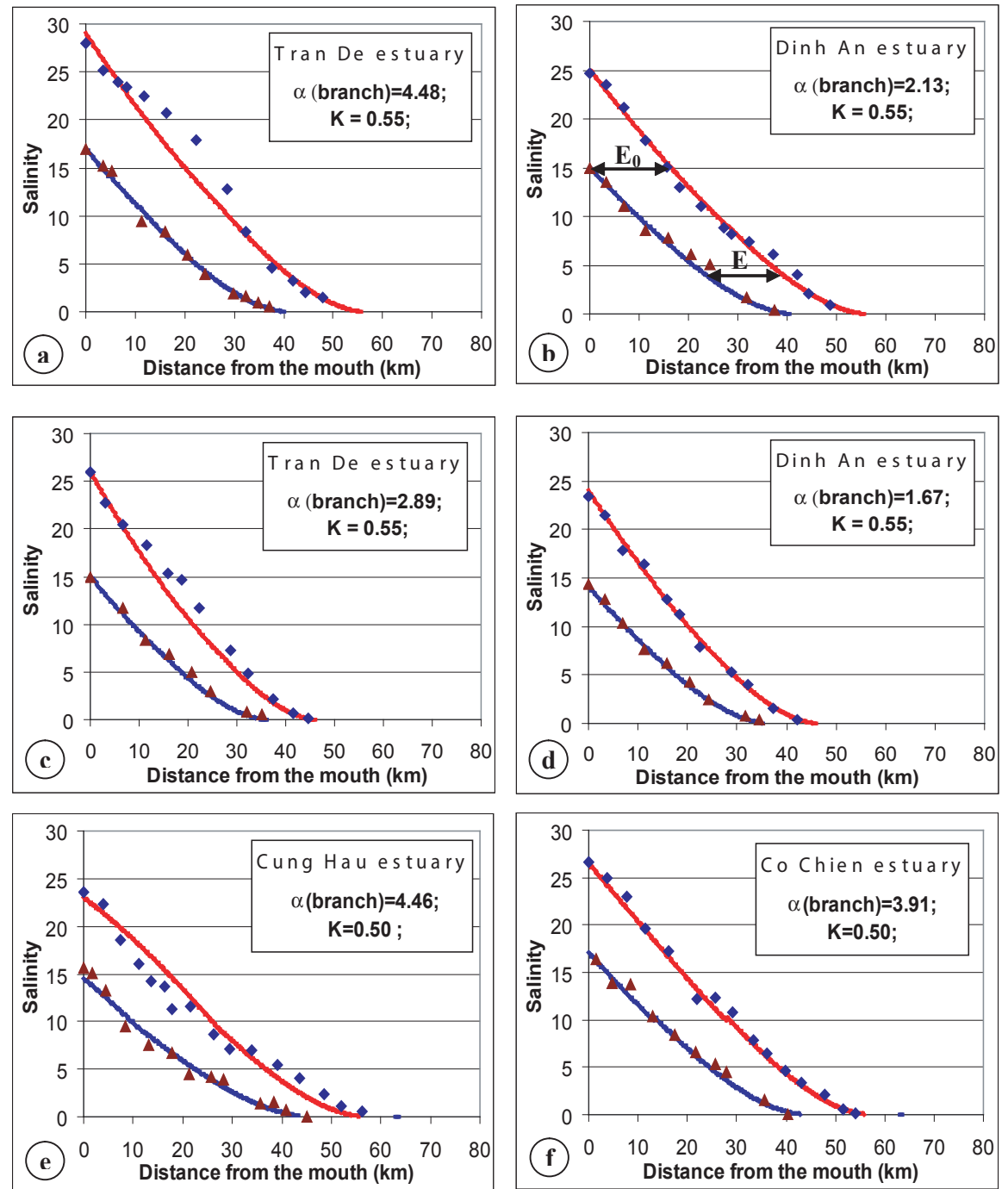

Fig. 6. Salinity distribution of individual branches: (a) Tran De on 8 April, (b) Dinh An on 9 April, (c) Tran De on 21 May, (d) Dinh An on 22 May, (e) Cung Hau on 21 April and (f) Co Chien on 22 April 2005, showing values of measured salinity at HWS (diamonds), and LWS (triangles), and calibrated salinity curves at HWS (red curve) and LWS (blue curve).

piers, churches, temples, gauges, etc.). Additionally a GPS device is used to obtain the exact co-ordinates of the locations. The measurement starts at the mouth in mid-stream. While anchored one waits until the moment of slack occurs. The first observation is done at slack tide, measuring at different points over the depth. Travelling at a velocity of 25 $30 \mathrm{~km} / \mathrm{h}$ one can arrive at the next location just a few minutes before slack. One then stops the boat and waits until the slack moment occurs (either by anchoring or by closely watching the shores or the GPS as one drifts). At slack one does a quick measurement over the full depth at one meter intervals starting from the bottom with a conductivity meter with a 10-m cable. Measurements are done in mid-current.

The first and second survey were carried out at the moment of LWS and HWS on 8 April and 9 April during spring tide in the Tran De and Dinh An branches. The third and fourth survey in the Hau river were conducted on 21 May in Tran De and on 22 May in Dinh An. The field measurements in the Co Chien and Cung Hau estuary branches were carried out on 21 and 22 April at the moments of LWS and HWS during spring tide.

The second data set is obtained from the network of fixed stations near intakes and quays, which measure salinity values during the dry season at hourly intervals.

During the moving boat measurements, we managed to measure vertical salinity distribution at several points in the Dinh An, Tran De, Co Chien and Cung Hau branches. It appeared that these branches are partially-mixed and wellmixed estuaries corresponding to the classification of Dyer (1997, chapter 2). 
River discharge and tidal data during the 2005's field measurements provided by the Vietnamese National Hydrometeorology Services are summarized in Table 2. One can see that within two successive days river discharge and tidal range variations are small, and therefore salinity variations between successive HWS and LWS situations are supposed to be small as well.

\section{Salinity computation for the Mekong Delta estuaries}

In this section, two approaches are used to compute the salinity distribution in the Mekong Delta estuaries.

The first approach considers every single branch as an individual estuary and Savenije's (2005) method is used to determine the longitudinal salinity distribution.

Because of the similarities between the estuary branches, the second approach considers the combination of paired estuary branches as a single estuary. Here, the method is applied under some modifications. Compared to the first approach, the second approach offers better results, which is subsequently validated against historic observations at fixed locations. Finally, based on calibrated and validated results of the second approach, a predictive model for the Mekong Delta estuaries is proposed.

\subsection{Approach 1: Analysis of individual branches}

The first approach considers every single branch as an individual estuary (i.e. Tran De, Dinh An, Cung Hau, Co Chien). The channel topography of each estuary is shown in Table 1. Using Eqs. (4) and (5), we can compute the longitudinal variation of the salinity in every individual estuary. The calibrated results, based on measurement data of $8,9,21,22$ April and 21, 22 May, 2005, are presented in Fig. 6.

One other thing we can conclude from the measurement data is that the tidal excursion, which is the distance that a water particle travels between LWS and HWS (and hence the horizontal distance between the drawn curves) is damped along the estuary branches. This is due to the considerable discharge of the Mekong even during dry seasons. The tidal excursion in the Hau and the Co Chien - Cung Hau branches can be described by an exponential function, i.e. $E=E_{0} \ln \left(-\frac{x}{e}\right)$ where $E(\mathrm{~L})$ is the tidal excursion at location $x(\mathrm{~km})$ from the mouth, $E_{0}(\mathrm{~L})$ is the tidal excursion at the mouth and $e(\mathrm{~L})$ is the damping length. $E_{0}$ is determined by the horizontal distance between the LWS salinity curve and the HWS salinity curve at the mouth (See an example in Fig. 6b). $E_{0}$ and $e$ are determined by fitting against the longitudinal salinity distributions.

We can see from Fig. 6 that the method can be used to describe the salinity distribution in the individual branches of the Hau and the Co Chien - Cung Hau. The measured data in the Dinh An estuary branch can be considered to be
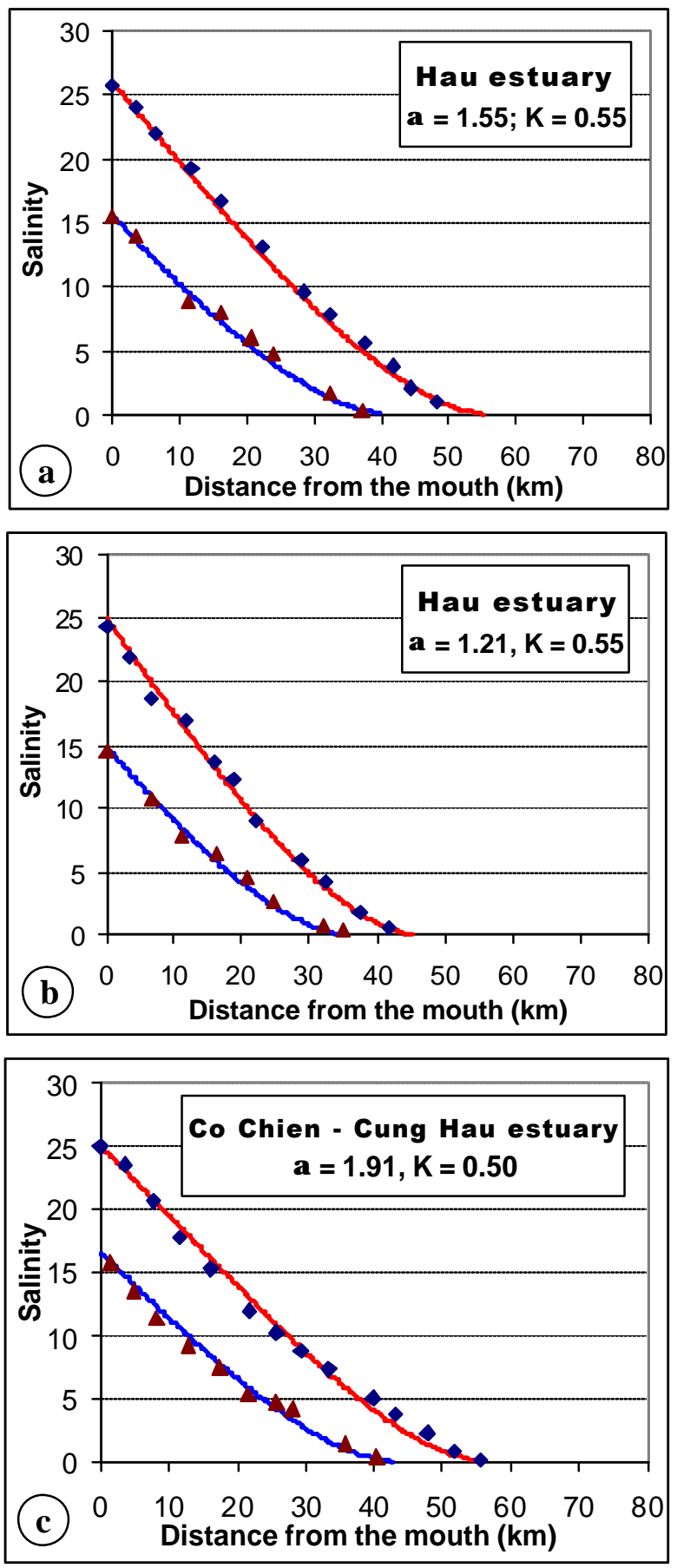

Fig. 7. Salinity distribution of (a) The Hau estuary (combination of Tran De and Dinh An branches) on 8 and 9 April, 2005; (b) The Hau estuary on 21 and 22 May, 2005; and (c) The Co Chien - Cung Hau estuary (combination of Cung Hau and Co Chien branches) on 21 and 22 April, 2005, showing values of measured salinity at HWS (diamonds), and LWS (triangles), and calibrated salinity curves at HWS (red curve) and LWS (blue curve). 

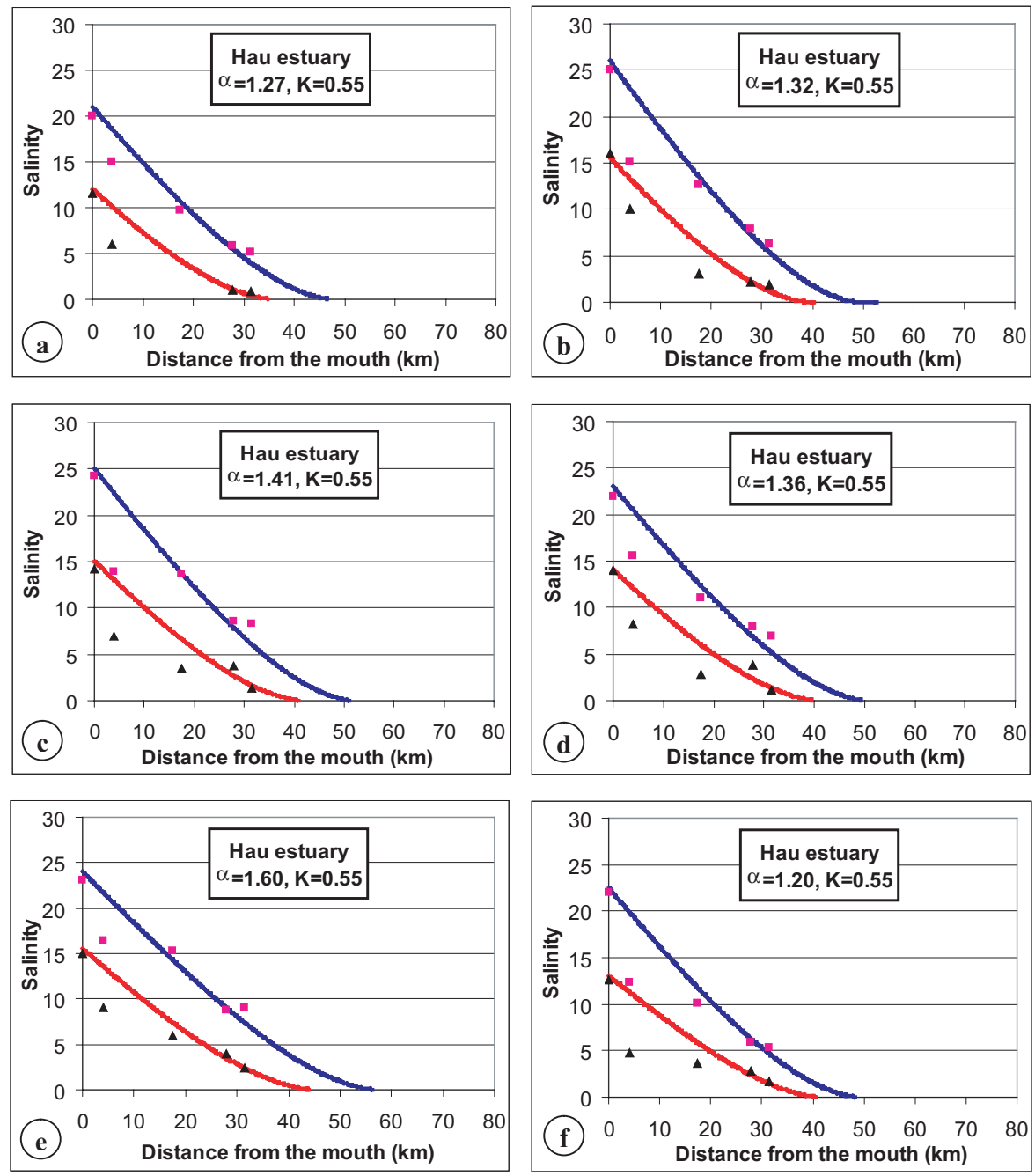

Fig. 8. Validation results of the Hau (combination of Tran De and Dinh An) estuary: (a) on 01 March 1998; (b) 05 April 1998 ; (c) 07 April 1998; (d) 02 March 1999; (e) 20 March 1999 and (f) 16 April 1999, showing values of observed salinity at HWS (diamonds) and LWS (triangles), and calibrated salinity curves at HWS (blue curve) and LWS (red curve).

the best thanks to the navigation buoys that gave the authors a clear view of the occurrence of HWS and LWS.

\subsection{Approach 2: Combination of two branches into a single estuary}

The second approach considers the combination of two paired branches as a single estuary branch. The combination of the Dinh An and Tran De branches is named "Hau estuary" and the combination of the Co Chien and Cung Hau branches is named "Co Chien - Cung Hau estuary". The channel topography of the combined estuaries is shown in Table 1 and Figs. $4 \mathrm{c}$ and $5 \mathrm{c}$. The salinity of one combined estuary is taken as a weighted mean between the cross-sectional areas of the branches. Using Eqs. (4) and (5), we can compute the longitudinal variation of the salinity in every combined estuary. The calibrated results for the combined estuaries are presented in Fig. 7.

One can see that the second approach produces very good results. The overall performance is better than that of the first approach. This underlines the assumption that the estuary system functions as an entity.

We can observe that the mixing coefficients of the individual branches in Fig. 6 are always higher than those values of the combined estuaries in Fig. 7. This is understandable since the river discharge is split over the two branches, while the tidal range remains the same. As a result, $\alpha_{0}$ is bigger in the individual branches than in the combined branches. 

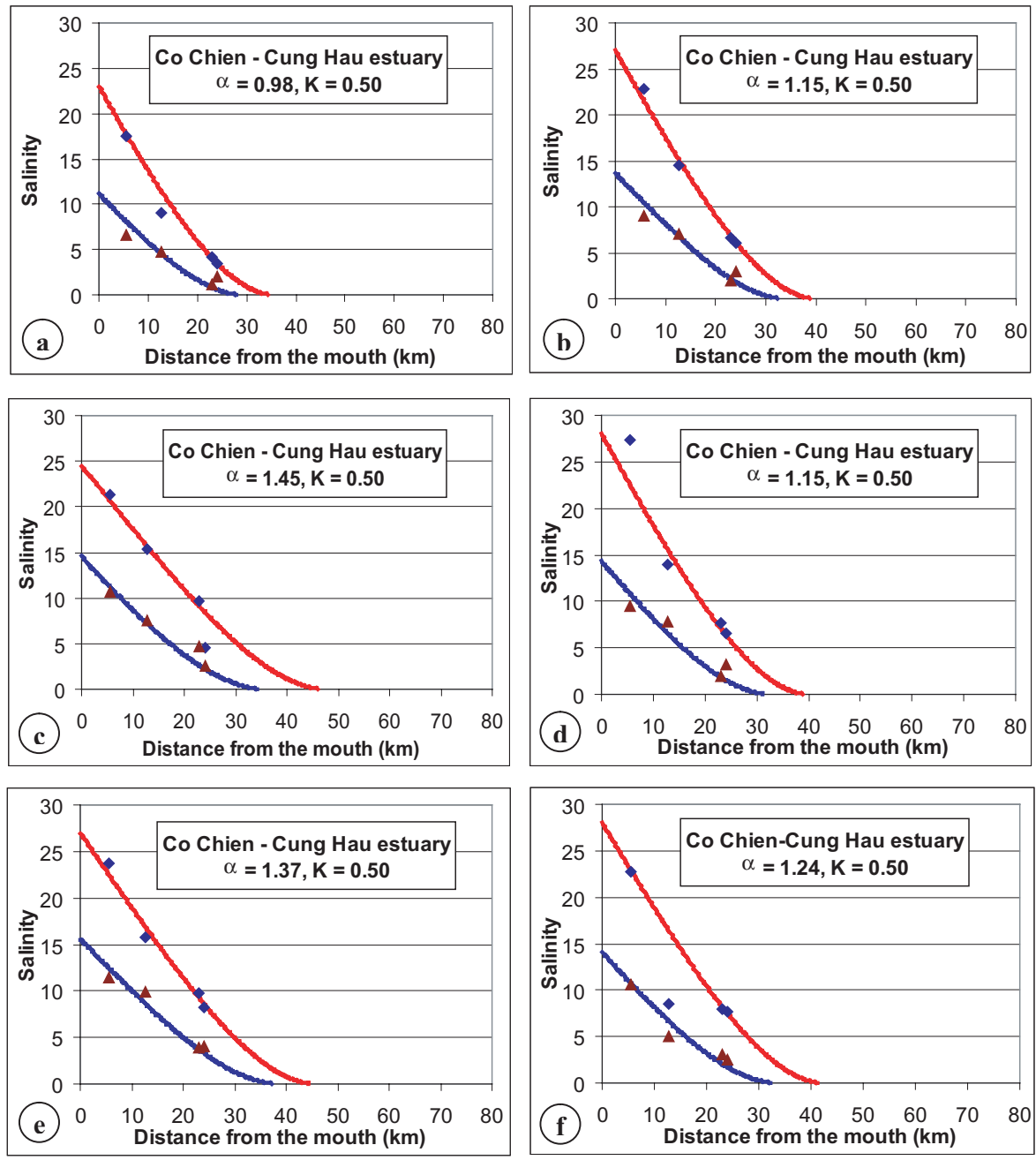

Fig. 9. Validation results of the Co Chien - Cung Hau (combination of Cung Hau and Co Chien) estuary: (a) on 16 March 1998 ; (b) 02 April 1998; (c) 15 April 1998; (d) 02 March 1999; (e) 21 March 1999 and (f) 19 April 1999, showing values of observed salinity at HWS (diamonds) and LWS (triangles), and calibrated salinity curves at HWS (red curve) and LWS (blue curve).

\subsection{Validation of Approach 2}

As we mentioned in Sect. 4, in the Mekong delta, there is a network of fixed stations near intakes and quays, which measure salinity values during the dry season at hourly intervals. Unfortunately, this information is not ideal since it does not permit the direct derivation of the longitudinal distribution of the maximum and minimum salinity (i.e. salinity at LWS and HWS), partly because they are often not located near the main current (sometimes they are located within a canal opening or intake), and partly because of the timing. However, we shall use these maximum and minimum daily values as indicators for the HWS and LWS salinity, to validate the model.
The validated results are presented in Fig. 8 (for the combined Hau estuary) and Fig. 9 (for the Co Chien - Cung Hau estuary).

Generally, the model performs reasonably well, especially at HWS. At several stations, e.g. Tra Kha $(4 \mathrm{~km}$ from the Dinh An mouth) and Hung My (12.7 km from the Co Chien mouth), the observed salinity values are too small and inaccurate. This is to be expected since these stations are located in the mouth of a canal or close to the river banks.

\subsection{Predictive model}

Based on calibrated and validated results of the second approach (see Sects. 5.2 and 5.3), we can use Eqs. (7) and (8) to turn the salinity model of the Mekong Delta into a 


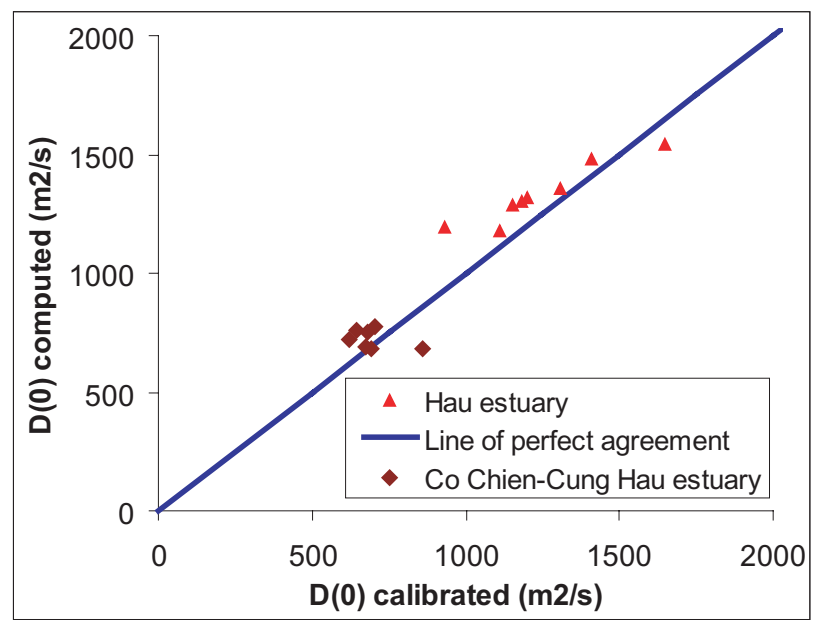

Fig. 10. Empirical relation for $D_{0}^{\mathrm{HWS}}$ for the Hau estuary and the Co Chien-Cung Hau estuary.

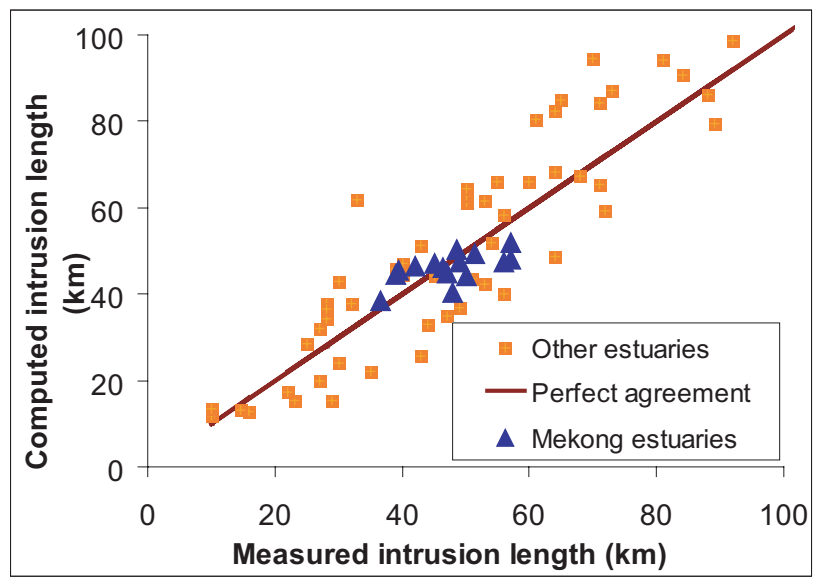

Fig. 11. Salt intrusion length at HWS according to the modified predictive model, applied to the Mekong and other estuaries described by Savenije (2005).

predictive model. The values of $K$, obtained from calibration, are 0.55 and 0.50 for the Hau and the Co Chien-Cung Hau respectively, which compare fairly well with predicted values of 0.42 and 0.45 , which are computed by Eq. (8). Similarly, the calibrated values of $D_{0}^{\mathrm{HWS}}\left(D_{0}^{\mathrm{HWS}}=\alpha_{0}^{\mathrm{HWS}} Q_{f}\right.$, where $Q_{f}$ is known from the discharge measurement and $\alpha_{0}^{\mathrm{HWS}}$ is obtained through calibration against the observed longitudinal salinity distribution) for the Hau estuary and the Co Chien - Cung Hau estuary should be compared to Eq. (7). We notice that the calibrated values of $D_{0}^{\mathrm{HWS}}$ for the measurement described in Figs. 8 and 9 fit Eq. (7) well (see Fig. 10) if we use $b$ (i.e. the width convergence length) instead of $a$ (i.e. the area convergence length) and if the average depth over the salinity intrusion length is taken instead of the depth at the estuary mouth.
For the Hau estuary and the Co Chien-Cung Hau estuary, the predictive equation then reads:

$D_{0}^{\mathrm{HWS}}=1400 \frac{\bar{h}}{b} \sqrt{N_{R}}\left(v_{0} E_{0}\right)$

In Fig. 11, these results are plotted together with the estuaries presented by Savenije (2005, page 171). What we observe in Fig. 11 is that the salt intrusion lengths at HWS of the Hau and the Co Chien-Cung Hau computed by the modified predictive model using Eq. (13) and Eq. (6) (blue triangles) plot very well within the set. To permit a good comparison, the intrusion lengths in the other estuaries have also been computed using Eq. (13).

\section{Discussion}

One thing we have to bear in mind is that the method presented in the Sect. 5 is applicable to a steady state salinity distribution. Estuaries require a certain time to adjust to changes in the boundary conditions before they reach a steady state equilibrium. Savenije (2005, p. 175) found that the system response times for different estuaries are in the order of magnitude of days to months. From Eq. (9), we computed the system response time for the Mekong estuaries. The computed system response times for the Hau estuary on 8 April, 2005 and 21 May, 2005 and the Co Chien-Cung Hau estuary on 21 April, 2005 are 7 days, 18 days and 3 days, respectively. In relation to the low variability of the discharge during the dry season, these values indicate that the estuary system is capable of adjusting itself to a new situation, and doesn't lag far behind an equilibrium state during the dry season. Therefore, we can use the steady state method to compute the salinity distribution in the Mekong estuaries.

The Mekong delta has a network of fixed stations along the banks, which measure salinity values during the dry season. These stations provide hourly salinity observations. Unfortunately, these values are not very adequate for the HWS-LWS method. For validation, we took the maximum and minimum daily values of the salinity at these stations and we assumed that these values are close to HWS and LWS values in the same day. This assumption is rather weak because the stations are generally not located near the centre of the stream but rather in the lee, often near intakes of canals.

The Van der Burgh's coefficient, $K$, has been taken from the calibrated process from field data in 2005 . These values compare fairly well with the predictive Eq. (8). We should realise that the predictive equation for $K$ is still rather weak and may have to be improved in the future. Therefore, the calibrated $K$ values for the Hau and the Co Chien - Cung Hau estuaries are considered to be the most reliable. For a detailed explanation on Van der Burgh's coefficient reference is made to Savenije (2005, p. 133-168).

There are several limitations in this study. Firstly, there is lack of updated topographical data of the Mekong Delta. The 
data used in this paper are obtained from the surveys carried out between 1991 and 1998. Later, the Mekong Committee developed a topographical database of the lower Mekong Delta, but this database is essentially composed of the same data with only minor modifications and updates. As we know, the Mekong Delta is morphologically active and the topography is continuously changing due to the high sediment transport capacity of the river. Hence, there still is room for improvement of the salinity model by using more recent topographical data.

The predictive model is sensitive to a number of parameters that have a certain degree of uncertainty. These are the mean estuary depth $\bar{h}$ and the river discharge $Q_{f}$. There is uncertainty in the determination of the average depth over the cross-section, particularly when (for instance in the Dinh An) there is a shallow part and a deep part, and when the estuary depth is not constant (there is a slight bottom slope). Similarly, there is an effect of a possible error in river discharge. In the Tien and Hau rivers, there are two discharge stations located at Tan Chau (Tien river) and Chau Doc (Hau river) (see Fig. 2). Normally, the discharge at Tan Chau is 3 to 5 times larger than the discharge at Chau Doc. One special thing is that just $20 \mathrm{~km}$ downstream of Tan Chau and Chau Doc, there is a connecting river called Vam Nao, which conveys water from the Tien to the Hau river. The discharge ratio between the Hau and the Tien rivers after the Vam Nao changes substantially. Unfortunately, we do not have sufficient data to obtain the actual discharge ratio between the Hau and the Tien after the Vam Nao connection. However, there are several existing numerical models that provide an estimation of the ratio. The discharge is important since it directly influences the dispersion coefficient, especially at the mouth $\left(D_{0}\right)$ (see Eq. 7), which affects the salinity distribution in the estuary.

From existing hydrodynamic models, we derived a discharge ratio between the Hau and the Tien river of 53\%/47\% of the total discharge. From updated computations (Southern Institute for Water Resources Research, Vietnam, unpublished), this ratio has been changed to $55 \% / 45 \%$ or even $60 \% / 40 \%$, as a result of the construction of inland canals and channel networks, which convey water from the Hau to the Tien river. Due to the active morphology, we may expect modifications in the delta topography. As a result, the discharge distribution between estuary branches may change overtime and hence it is uncertain.

The uncertainty in the average depth may be reduced by using the analytical relations for tidal damping and wave propagation presented by Savenije (2005, 2001), Savenije and Veling (2005), but this will require additional observations of tidal damping, wave propagation and longitudinal salinity distributions.

Both the uncertainties in the average depth and the discharge are relevant for the accuracy of the predictive model. In fact, salinity observation in combination with the model can help to ascertain the discharge distribution over the estuary branches.

\section{Conclusions}

In this paper, the theory for the computation of salt intrusion in single alluvial estuaries described by Savenije (2005) is for the first time applied to the Mekong delta, Vietnam, which is a riverine multi-channel estuary with increasing depth in upstream direction and damped tidal excursion. Although the theory has not been developed for this situation, it is well applicable if we combine paired estuary branches and modify Eq. (7) into Eq. (13).

In view of the similar hydraulic, topographical and salinity characteristics of the branched estuaries in the Mekong, it is concluded that the multi-channel estuarine system functions as an entity and that paired branches should be considered as a single estuary branch. This procedure has been successfully applied and tested in the Dinh An and Tran De branches (the combined estuary named the Hau estuary) and the Co Chien and Cung Hau branches (the combined estuary named the Co Chien - Cung Hau estuary). Based on salinity measurements during the dry season of April and May 2005, an analytical model has been developed to compute the longitudinal salinity distribution (at HWS and LWS) for the combined estuaries, e.g. the Hau estuary and the Co Chien Cung Hau estuary. The model has been validated with data of the dry seasons in 1998 and 1999. The overall results of salinity computation indicate that the assumption of combined branches is acceptable and that the simplified method can produce satisfactory results for a complex system such as the Mekong delta.

Acknowledgements. The authors would like to acknowledge the Southern Institute for Water Resources Research (SIWRR), Ho Chi Minh City, Vietnam for their enthusiastic supports during the data collection period and the field measurement campaign. We are particularly grateful to Le Sam, Tang Duc Thang and Nguyen Van Sang (SIWRR), who kindly provided the database of the Mekong Delta salinity, topography and hydrology.

Edited by: A. D. Reeves

\section{References}

Dyer, K. R.: “Estuaries, A Physical Introduction”, second ed. John Wiley, London, 195 pp, 1997.

Nguyen, A. N. and Nguyen, V. L.: Salt water intrusion disaster in Vietnam. UNDP Project No VIE/97/002, HCM City, Vietnam (in Vietnamese and English), 1999.

Savenije, H. H. G.: A one-dimensional model for salinity intrusion in alluvial estuaries, J. Hydrol., 85, 87-109, 1986.

Savenije, H. H. G.: Salt intrusion model for high-water slack, lowwater slack and mean tide on spreadsheet, J. Hydrol., 107, 9-18, 1989. 
Savenije, H. H. G.: Rapid Assessment Technique for Salt intrusion in alluvial estuaries, Ph.D. thesis, IHE report series, No. 27, International Institute for Infrastructural, Hydraulic and Environmental Engineering, Delft, The Netherlands, 1992.

Savenije, H. H. G.: Predictive model for salt intrusion in estuaries, J. Hydrol., 148, 203-218, 1993.

Savenije, H. H. G.: A simple analytical expression to describe tidal damping and amplification, J. Hydrol., 243, 205-215, 2001.
Savenije, H. H. G.: Salinity and Tides in Alluvial Estuaries, Elsevier, Amsterdam, 197pp, 2005.

Savenije, H. H. G. and Veling, E. J. M.: Relation between tidal damping and wave celerity in estuaries, J. Geophys. Res., 110, C04007, 1-10, 2005.

Van der Burgh, P.: Ontwikkeling van een methode voor het voorspellen van zoutverdelingen in estuaria, kanalen en zeeen, Rijkwaterstaat Rapport 10-72 (in Dutch), 1972. 